УДК 536.242:532.242

\title{
РАБОТЫ ИНСТИТУТА ТЕХНИЧЕСКОЙ ТЕПЛОФИЗИКИ В РЕШЕНИИ ПРОБЛЕМ РАЗРУШЕННОГО РЕАКТОРА И СТРОЯЩЕГОСЯ КОНФАЙНМЕНТА (К 30-ЛЕТИЮ АВАРИИ НА ЧЕРНОБЫЛЬСКОЙ АЭС)
}

\author{
Грищенко Т.Г., Д.Т.н., Круковский П.Г., Д.т.н., Коваленко Г.В., К.Т.Н., \\ Декуша Л.В., к.т.н., Воробьев Л.И., к.т.н., Метель М.А., к.т.н., Полубинский А.С.
}

Институт технической теплофизики НАН Украины, ул. Желябова, 2 а, Киев, 03680, Украина

Зроблено огляд робіт, що виконувались співробітниками ІТТФ НАН України для ліквідації наслідків аварії на 4-му блоці Чорнобильської АЕС 26 квітня 1986 р. Так для виявлення i дослідження місць скупчення ядерного палива i паливовмісних мас були розроблені i виготовлені перетворювачі теплового потоку і температури. Виконувалася розрахункова робота 3 прогнозування можливого розігріву зруйнованого реактора внаслідок заповнення його різними матеріалами (бетоном, керамзитом i обрізками сталевих труб). Побудовано комп'ютерні моделі і коротко представлені результати аналізу i прогнозування термогазодинамічних процесів в Новому Безпечному Конфайнменті та «Об'єкті Укриття» Чорнобильської АEC 3 метою перевірки підтримання заданих параметрів i працездатності ряду інженерних систем.

Рис. 15.
Представлен обзор работ, выполненных сотрудниками Института технической теплофизики НАН Украины для ликвидации последствий аварии на 4-м блоке Чернобыльской АЭС 26 апреля 1986 г. Так для выявления и исследования мест скопления ядерного топлива и топливосодержащих масс были разработаны и изготовлены преобразователи теплового потока и температуры. Выполнялась расчетная работа по прогнозированию возможного разогрева разрушенного реактора вследствие заполнения его различными материалами (бетоном, керамзитом и обрезками стальных труб). Построены компьютерные модели и кратко представлены результаты анализа и прогнозирования термогазодинамических процессов в Новом Безопасном Конфайнменте и «Объекте Укрытие» Чернобыльской АЭС с целью проверки поддержания заданных параметров и работоспособности ряда инженерных систем.
An activities review of employees of IETP of NAS of Ukraine on the mitigation of the implications of the accident at Unit 4 of the Chernobyl nuclear power plant, April 26, 1986 is shown. To identify and study nuclear fuel and fuel-containing material accumulation places heat flow and temperature transducers have been developed and manufactured. The work on the forecasting of probable warming up of the destroyed reactor due to being filled with various materials (concrete, expanded clay and scraps of steel pipes) was performed. Computer models were developed and the results of the analysis and forecasting of heat and gas dynamic processes are presented for the New Safe Confinement and "Object Shelter" of the Chernobyl nuclear power plant in order to verify the fitting to defined criteria of engineering systems performance.

Ключевые слова: авария на Чернобыльской АЭС, теплотехнические измерения, преобразователи теплового потока и температуры, моделирование теплового состояния, конфайнмент.

В ночь на 26 апреля 1986 г. на 4-м блоке ЧАЭС произошла крупнейшая из аварий, которые знала атомная энергетика. В результате взрыва была полностью разрушена активная зона и вся верхняя часть здания реактора, сильно пострадали и другие части блока (рис. 1).

Были уничтожены барьеры и системы безопасности, защищавшие окружающую среду от радионуклидов, наработанных в облученном топливе. Выброс активности из поврежденного реактора на уровне миллионов кюри в сутки продолжался в течение 10 дней с 26.04.86 по 06.05.86, после чего резко упал (в тысячи раз) и в дальнейшем продолжал уменьшаться.

Авария на ЧАЭС так или иначе затронула жизнь миллионов людей. Сотни тысяч из них были эвакуированы с загрязненных территорий Украины, России, Белоруссии. Другие сотни тысяч 
непосредственно участвовали в создании «Объекта Укрытия» (ОУ) над разрушенным 4-м блоком, в дезактивации площадки ЧАЭС и других блоков, в работах в чернобыльской зоне отчуждения и временного отселения, в строительстве города Славутич и т.п.

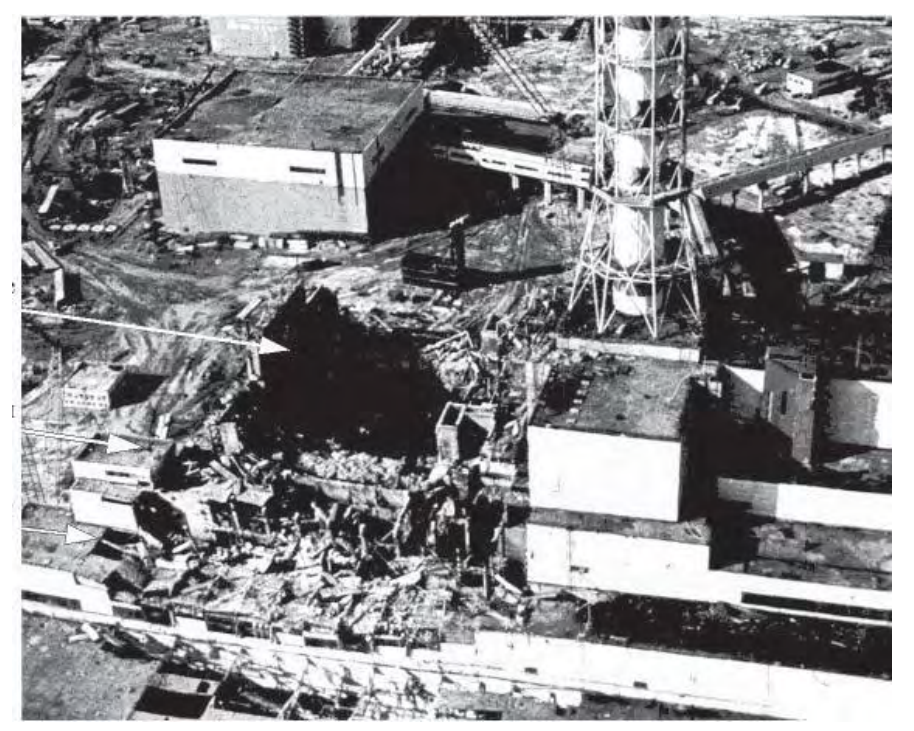

Рис. 1. Разрушенный 4-ый блок ЧАЭС (май 1986 г.).

Сразу после аварии и за прошедшие 30 лет инженерами, рабочими и научными сотрудниками украинских и зарубежных организаций был выполнен огромный объём работ по изучению и анализу состояния ОУ, стабилизации его конструкций, а также проектированию и строительству дополнительных сооружений для ликвидации последствий аварии.

В статье кратко изложены работы, выполненные и выполняющиеся на протяжении 30 лет сотрудниками Института технической теплофизики НАН Украины (ИТТФ), для решения перечисленных выше задач.

\section{1.ТЕПЛОМЕТРИЧЕСКИЙ АНАЛИЗ РАЗРУШЕННОГО РЕАКТОРА}

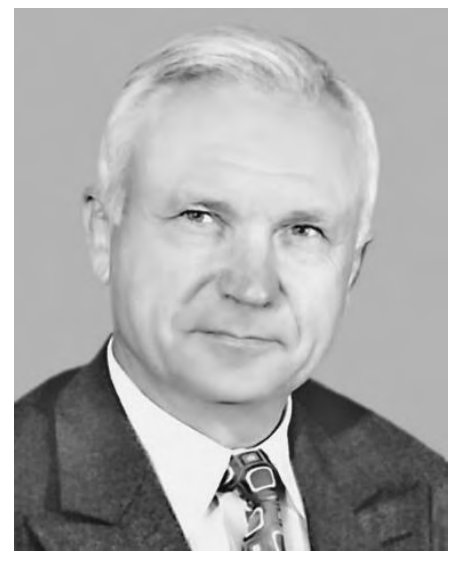

Непосредственно в зоне аварии сотрудники института начали работать 10 мая 1986 г. В этот день по приглашению академика АН СССР Б.П. Велихова в г. Чернобыль прибыл чл.-кор. АН УССР О.А. Геращенко (см. фото) для обсуждения вопросов организации постоянных измерений температуры и теплового потока на развале четвертого блока ЧАЭС. Главная задача после 26 апреля 1986 г. состояла в том, чтобы не допустить повторения аварийного выброса радиоактивных веществ. Для этого необходимо было обследовать состояние разрушенного четвертого блока и выявить потенциально опасные скопления ядерного топлива в условиях высокого уровня радиации в помещениях блока и на промплощадке. Обломки тепловыделяющих элементов и топливосодержащие массы (ТСМ), выкинутые в результатевзрыва из шахты реактора и разбросанные по всей территории промплощадки, являлись локальными источниками радиоактивного излучения очень высокой интенсивности. Особенно много их находилось в центральном машинном зале и на крышах машзала и соседнего третьего блока.

Для диагностики энергетического состояния огромной зоны объемом $105 \mathrm{M}^{3}$, а затем для выявления и исследования мест скопления ядерного топлива и ТСМ на ЧАЭС, а позже на объекте «Укрытие» среди различных практически испытанных методов с наибольшей эффективностью 
проявил себя теплометрический метод. Этот метод предусматривал применение первичных измерительных преобразователей теплового потока (ПТП) и температуры (ПТ) для определения аномальных тепловых источников и характера их пространственного распределения, что позволило оперативно оценить места скопления ТСМ и уточнить количество ядерного топлива, оставшегося в объекте.

Начиная с 10 мая 1986 г. в ИТТФ непрерывно (почти круглосуточно) выполнялась разработка и изготавливались ПТП и другие необходимые средства измерительной техники. С их применением регулярные измерения стали проводить с июня, когда по результатам дозиметрической и визуальной разведок были составлены атласы радиоактивной обстановки во всех доступных помещениях аварийного блока и выявлены сравнительно безопасные подходы к наиважнейшим узлам разрушенного реактора и местам ожидаемого размещения выброшенного ядерного топлива.

ПТП, будучи наклеенными в нескольких местах на стены барботера, дали первую объективную информацию о тепловой стороне протекавших процессов. Сколь актуально было получение этой информации, можно судить на примере развития ошибочной гипотезы, родившейся в первые дни после аварии и сводившейся к тому, что в центральной части разрушенного реактора возник плазменный сгусток с температурой 15000 К, который мог проплавить несколько одно- и двухметровых перекрытий и провалиться в грунт под основание реактора. Главная опасность усматривалась в том, что дальнейшее его непредсказуемое движение при непредсказуемой мощности будет невозможно остановить. Для ограничения этой угрозы было принято решение о сооружении под реактором водоохлаждаемой железобетонной плиты. Только после завершения этого строительства вспомнили о том, что при температуре 15000 К плотность плазмы на порядок меньше плотности воздуха, и сгусток плазмы, если бы он существовал, всплыл бы, а не погружался. Выполненные измерения позволили установить истинные максимальные значения теплового потока и температуры, которые оказались на два порядка ниже предполагаемых. Таким образом, в каком-то переносном смысле созданный буйной фантазией теоретиков сгусток плазмы был остановлен не колоссальной водоохлаждаемой железобетонной плитой, а несколькими ПТП.

a)

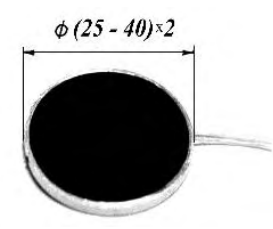

б)

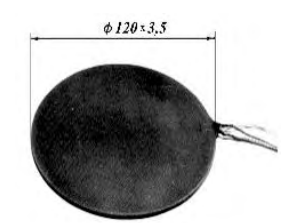

в)

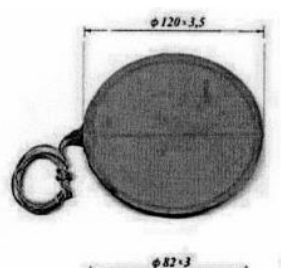

2)

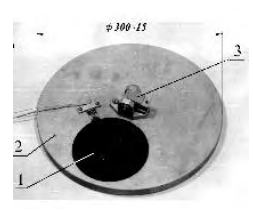

Рис. 2. Модели ПТП, использованные при диагностике теплового состояния 4-го энергоблока ЧАЭС: $а-П Т П-0.11 .13 .14 .00 ; б-П Т П-0.11 .14 .21 ; 6,2-\Pi T \Pi-0.11 .33 .14 .21$.

Сразу же после определения доступных помещений и путей к ним, способов и средств доставки измерительных элементов в зону, прилегающую к шахте реактора, были начаты работы по созданию системы оперативной диагностики и контроля физических параметров, обуславливающих тепловое и радиоактивное состояния разрушенного реактора. К этому сроку (конец мая - начало июня 1986 г.) в отделе теплометрии ИТТФ было уже разработано и изготовлено несколько моделей ПТП, показанные на рисунке 2. Несмотря на то, что уже имелся опыт разработки и изготовления различных ПТП и приборов на их основе, которые широко применялись во многих отраслях науки и техники, для экстремальных условий на ЧАЭС пришлось решать абсолютно новые задачи. 
Так ПТП, расположенные в зоне реактора, оказались на расстоянии до 1000 м от регистрирующей аппаратуры, на которую сигналы поступали по кабельной связи. Это потребовало создания ПТП не только с мощными выходными сигналами, но и способными длительное время сохранять стабильной свою чувствительность.

Доставку ПТП к месту их установки на стены разрушенных ограждающих конструкций и сохранившихся помещений выполняли добровольцы - «бойцы», а также средствами робототехники и вертолетом, но при этом установка ПТП на поверхности развала носила уже случайный характер. ПТП, предназначенные для доставки посредством вертолета, приклеивали к толстому металлическому диску. Такие ПТП с присоединенным кабелем связи опускали на фале с вертолета на запланированный участок развала, а второй конец кабеля, оформленный разъемом, сбрасывали в зоне, в которой был возможен доступ добровольца-бойца.

Для мониторинга понадобилось свыше 300 шт. ПТП различных моделей с разными техническими характеристиками. Их непрерывно изготавливали, отправляли на ЧАЭС и там устанавливали на объектах в зоне разрушенного энергоблока.

Поскольку размещение ПТП, доставляемых на развал энергоблока с помощью вертолета или крана «DEMAG», имело исключительно случайный характер, был разработан переносной прибор, позволявший оператору, находящемуся в относительно безопасной зоне, измерять одновременно плотность теплового потока и температуру, - прибор модели ИТП-Т, внешний вид которого показан на рис. 3.

Для упрощения обработки показаний вольтметра и получения измеряемой плотности теплового потока в условиях жесткого лимита времени применен встроенный в рукоятку жезла потенциометр,

a)

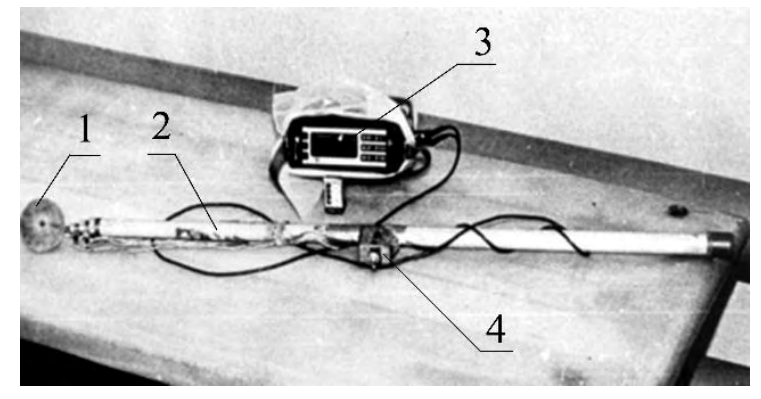

1 - ПТП; 2 - телескопический жезл («удилище»);

3 - цифровой вольтметр В7-35

4 - потенциометр;

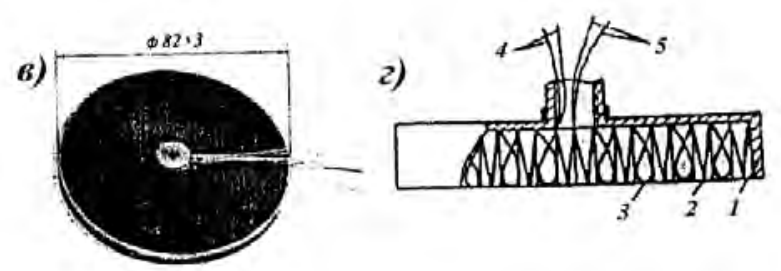

б)

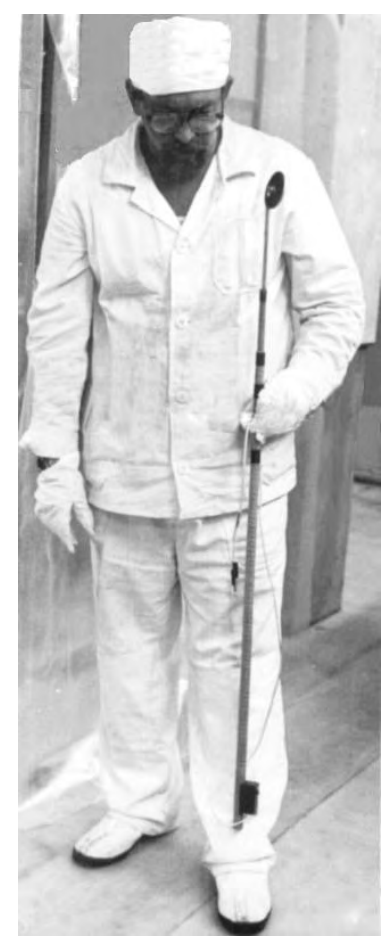

1 - корпус ПТП; 2 - термобатарея ПТП; 3 - спираль ТС; 4 и 5 -выводы ПТП и ТС

Рис. 3. а-Внешний вид переносного прибора для измерения теплового потока и температуры на поверхности разрушенного энергоблока ЧАЭС модели ИТП-Т;

б - сотрудник ИТТФ П.П. Бойко с «удилищем» переносного прибора ИТП-Т; в-ПТП в металлическом профилированном диске; г-схема конструкции ПТП. 
с помощью которого за счет некоторой потери чувствительности коэффициент преобразования был выведен на такое значение, которое позволило быстро фиксировать искомую плотность потока по показанию вольтметра в милливольтах умножением на 10.

Использование стеклопластикового удилища с возможностью удлинения до 4 м позволило оператору находиться на относительно безопасном расстоянии от объекта в условиях сильного ионизирующего излучения. Постоянные времени термобатареи и ТС на уровне соответственно, 25 с и 40 с позволили уменьшить время пребывания оператора в каждой точке замеров до 1,5...2 мин. Было изготовлено и передано Комплексной экспедиции "Укрытие" четыре таких прибора. С их помощью получено громадное количество экспериментальной информации о тепловых проявлениях на многих участках разрушенного энергоблока.

В условиях пораженной зоны развала четвертого блока ЧАЭС оказалось затруднительным непосредственное использование имеющейся теплометрической аппаратуры из-за большой радиационной опасности, так как доза ионизирующего излучения превышала несколько тысяч рентген в час. Для решения задачи температурного контроля поверхности развала был создан специальный термометрический буй (термозонд). В качестве термометрического явления была выбрана зависимость температуры плавления проволоки сплавов от их состава и массовой доли компонентов.

Термозонд (рис. 4) состоял из алюминиевого каркаса, на котором закреплены серьга под вертолетный фал и тросик, несущий подвешенные на поводках восемнадцать плавких колечек.

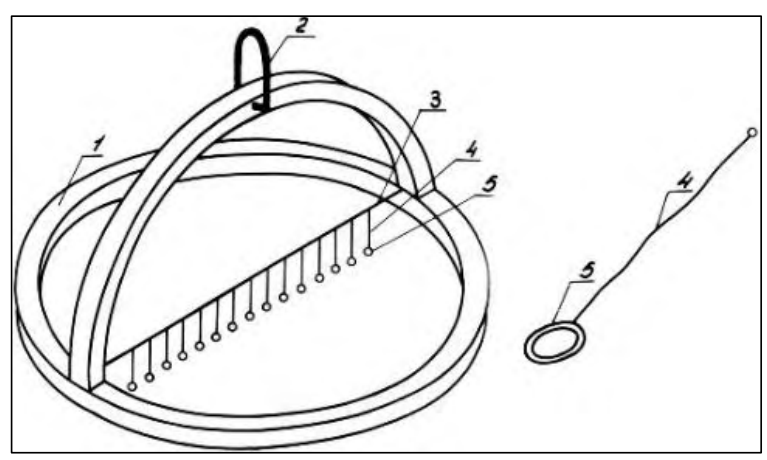

Рис. 4. Термозонд для определения температуры поверхности 4-го блока

ЧАЭС: 1 - алюминиевый каркас;

2 - серьга под вертолетный фал;

3 - трос крепежный; 4-поводки; 5 - плавкие кольца.
Колечки, выполненные из сплавов разного состава, обеспечивали индикацию температуры в диапазоне от $30^{\circ} \mathrm{C}$ до $300^{\circ} \mathrm{C}$. Измеренная температура в контролируемой точке равнялась температуре из интервала между значениями температуры последнего расправленного и первого сохранившегося колец, определяемых при осмотре после извлечения термозонда.

В пораженной зоне развала четвертого блока ЧАЭС оказалось весьма затруднительным наземное непосредственное применение теплотермометрической аппаратуры из-за большой радиационной опасности. Для первичной диагностики состояния разрушенного блока в Институте атомной энергии им. И.В. Курчатова (ИАЭ) и ИТТФ АН УССР были созданы специальные измерительно-диагностические буи, доставку которых на объект осуществляли вертолетом и краном «DEMAG».

В ИТТФ было создано две модели и изготовлено по одному экземпляру буев. Наиболее совершенной явилась вторая модель (рис. 5). Буй представлял собой шарнирную конструкцию, выполненную из алюминиевого сплава с тремя разнесенными под углом $120^{\circ}$ опорами (1) штангами (2) которые были держателями ПТП (3). Буй был снабжен фланцем (4) типа «сомбреро» внутрь которого кольцами укладывали измерительный кабель длиной 100 м, а также серьгой для крепления к транспортному фалу.

Оба экземпляра были доставлены в Чернобыль, однако наиболее массовыми буями, конструкция которых учитывала особенности установки на развал с помощью вертолетов, были диагностические буи ИАЭ. Они оказались более универсальными, так как содержали около двадцати первичных преобразователей различных физических величин, в том числе ПТП и ПТ, созданные в ИТТФ, то есть 20 \% всех измерительных каналов были отданы преобразователям ИТТФ.

Буй ИАЭ представлял собой металлическую конструкцию в виде полого усеченного 

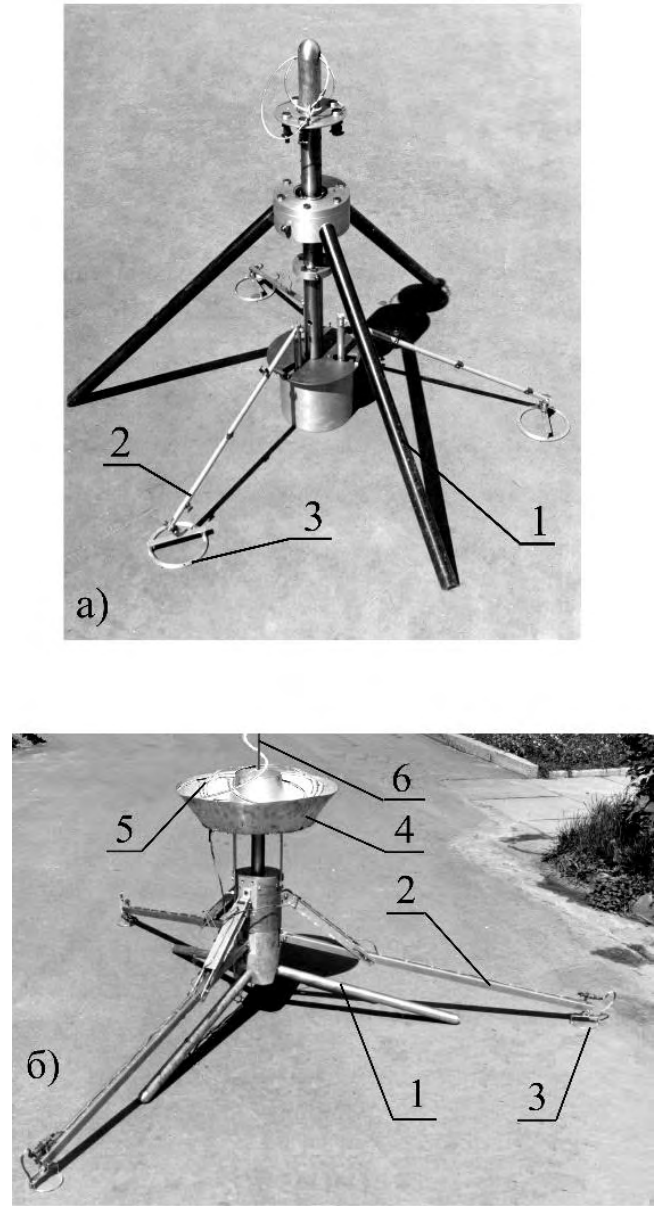

Рис. 5. а-первая модель диагностического буя ИТТФ;

б - вторая модель диагностического буя ИТТФ;

в - сотрудники ИТТФ зав. НИИ группой В.В. Василевская, главный конструктор проекта В. Нелипа -участники разработки диагностических буя.

1 -опоры; 2 - итанги-держатели ПТП; 3 - ПТП в кольце; 4-фланец "сомбреро»; 5 -кабель; 6-стальная проволока.

конуса (рис. 6).

Многие из различных преобразователей буев при транспортировании, а также в тяжелых температурных и радиационных условиях разрушенного реактора, выходили из строя еще на этапе установки. ПТП и ТП ИТТФ, как правило, работали безотказно. Всего было доставлено на поверхность реактора 15 действующих буев, с помощью которых на поверхности засыпки реактора было установлено около 150 действующих преобразователей различных физических величин, включая ПТП и ПТ ИТТФ. В течение 1986-1987 годов сотрудниками ИТТФ в аварийном режиме был разработан, изготовлен и поставлен на ЧАЭС комплекс специальной теплотермометрической аппаратуры для выполнения оперативного обследования разрушенного энергоблока. В результате в короткий срок была создана оперативная система контроля и диагностики тепловых параметров состояния разрушенного энергоблока. Примененная аппаратура позволила составить полную общую теплопоточную и температурную картины аварийной зоны. Наиболее существенные результаты,полученные с ее помощью, состоят в следующем:

- мониторинг состояния разрушенного реактора позволил предсказать последующее развитие изменений теплового состояния во времени; 


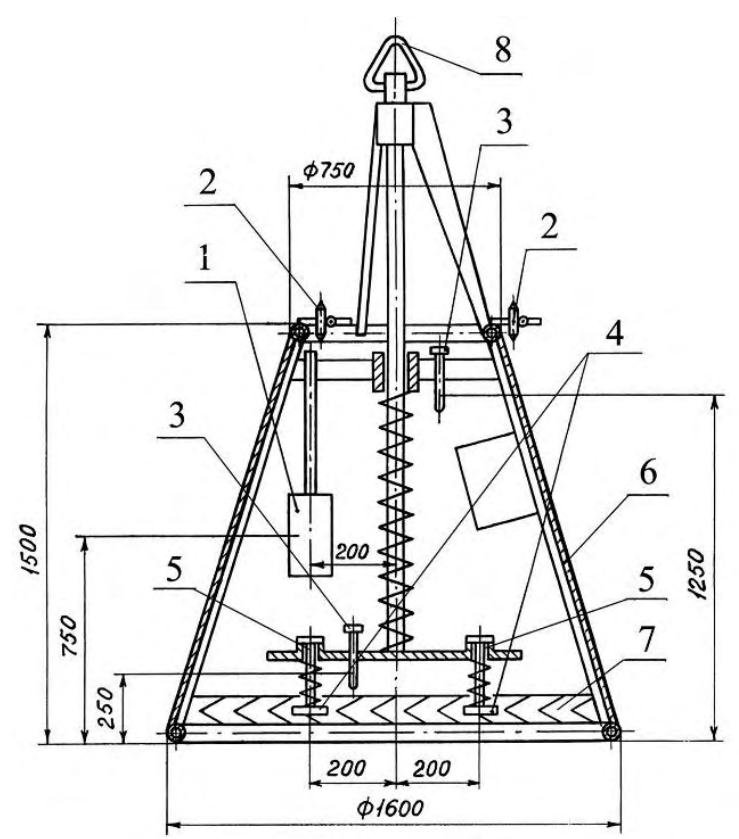

a)

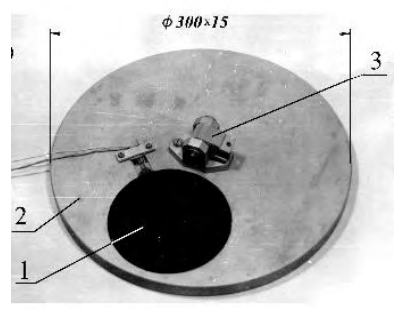

б)
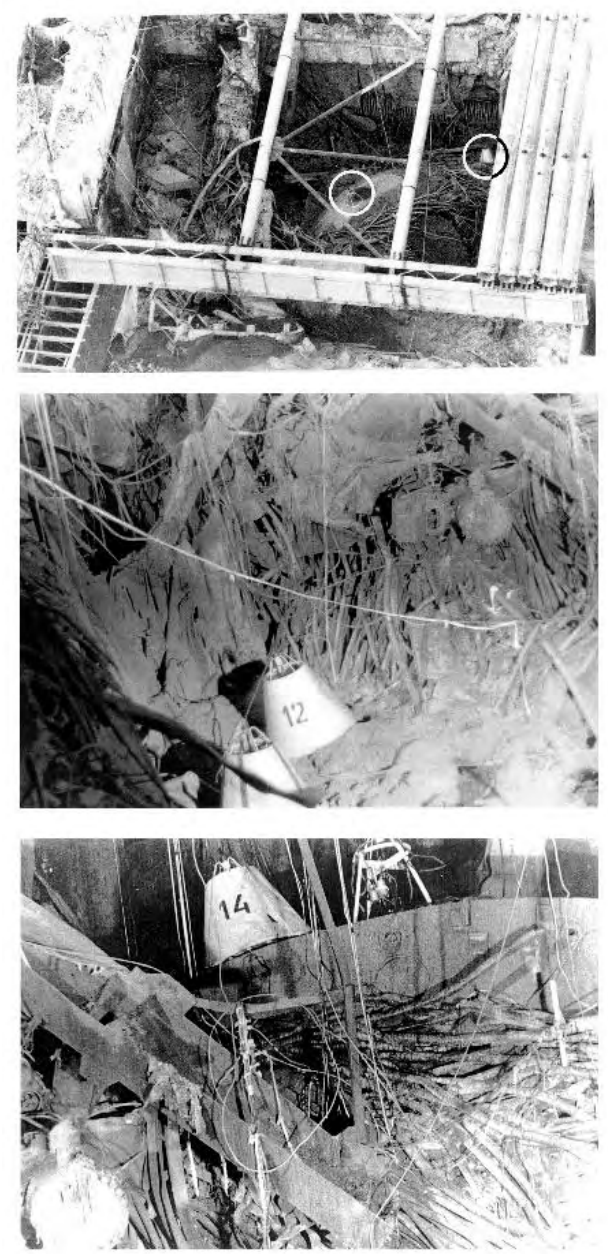

B)

Рис. 6. а-конструктивная схема диагностического буя ИАЭ АН СССР:

1 - подпружиненный стержень, который несет ПТП; 2- термометры сопротивления медные;

3 - ионизационная гамма-камера; 4- термоанемометры; 5 - кольцо под вертолетный фал;

6 - ПТП с никелевым термометром сопротивления; 7-кожух; основа из свинцовых слитков;

б-ПТП-0.11.33.14.21; в- диагностические буи ИАЭ СССР в актуальных точках разрушенного энергоблока.

- количественная оценка теплового баланса реактора №4 позволила установить, что количество оставшегося в реакторной зоне ядерного топлива превышает 87 \% от топливной загрузки реактора на момент аварии;

- детальное теплометрирование прилегающих к шахте реактора помещений и ограждающих строительных конструкций самой шахты позволило, с одной стороны, оптимизировать размещение первичных преобразователей оперативного контроля и, с другой стороны, показало наличие участков с повышенными плотностью теплового потока и температуры, тем самым помогло определить актуальные направления дальнейших диагностических исследований.

Активная работа по созданию средств измерения на объектах разрушенного энергоблока продолжалась несколько лет. В это время был проведен поиск по созданию новых моделей ПТП, отличающихся большей коррозионной стойкостью за счет двухслойных гальванических покрытий 
термоэлементов ПТП и стабильностью их эксплуатационных и метрологических характеристик. Кроме того, спустя почти 10 лет по заданию МНТЦ «Укрытие» в 1995-96 г.г. был разработан специальный микрокалориметр модели ДМК-1 для измерения остаточного тепловыделения в образцах ТСМ.

С начала систематических исследований аварийного энергоблока ЧАЭС (июнь 1986 г.) было установлено, что ядерное топливо находится в основном в составе застывших лавообразных скоплений, сосредоточенных в шахте реактора и прилегающих к ней подреакторных помещени-

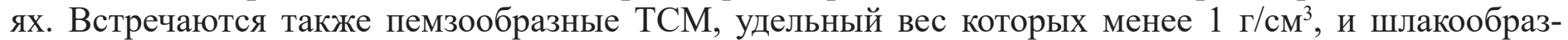
ные ТСМ, занимающие промежуточное положение между первыми и вторыми по удельному весу. В исследованных образцах топливо находится в виде мелкодисперсных частиц, вкрапленных в силикатную матрицу. Количество топлива в различных образцах ТСМ неодинаково, в отдельных образцах достигает 60 \% массы при среднем содержании около 10 \%. Тепловой эффект ТСМ определяется распадом долгоживущих радионуклидов и составляет по оценочным расчетам, в среднем, порядка 3 Вт на 1 т ТСМ, при условии, что все виды радиационного излучения поглощаются в образце. Экспериментальное определение столь малых значений мощности тепловыделения ТСМ представляет собой сложную техническую задачу, требующую применения высокочувствительного инструмента для измерения теплового потока в предполагаемом диапазоне значений $\left(10^{-4} . .1\right)$ Вт. Эта задача осложнена также тем, что исследуемые образцы ТСМ радиоактивны и мощность дозы гамма-излучения, как правило, составляет десятки бэр/ч.

Успехи в развитии теплометрии в Украине и опыт применения ПТП при исследовании тепловых процессов и эффектов в условиях повышенной радиации позволили разработать новое средство измерения мощности тепловыделения ТСМ-микрокалориметр модели ДМК-1, внешний вид и схема конструкции теплового блока предоставлены на рисунке 7.
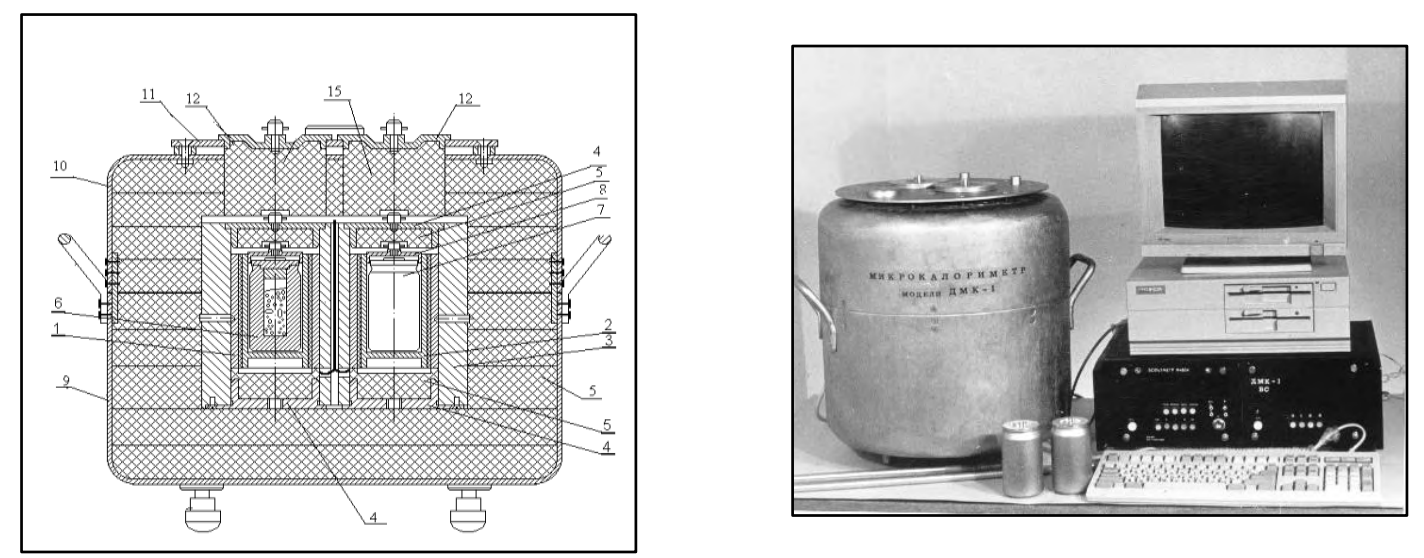

Рис. 7. Микрокалориметр ДМК-1: 1,2 - ячейки рабочая и сравнения;

3 - калориметрический блок; 4 - нижние и верхние крышки гнезд;

5 - вкладыши теплоизоляционные; 6, 7 - контейнеры; 8-крышки измерительных ячеек;

9, 10 - корпус, крышка корпуса; 11 - панель установочная, 12 - крышка.

Для обеспечения высокой чувствительности и необходимой точности измерения теплового эффекта в диапазоне значений $\left(10^{-4} \ldots 1\right)$ Вт в микрокалориметре используется дифференциальный метод измерения, с применением термоэлектрических ПТП вида цилиндрической вспомогательной стенки. По результатам государственной метрологической аттестации установлено, что предельно допускаемая относительная погрешность измерения мощности тепловыделения в диапазоне $\left(10^{-3} \ldots 2\right)$ Вт составляет $\pm 1,5 \%$, а в диапазоне $\left(10^{-5} \ldots 10^{-3}\right)$ Вт не хуже $\pm 5,5 \%$ при однократном 
измерений и \pm 2 \% при многократных измерениях. Таким образом, на момент создания, микрокалориметр может быть отнесен к уникальным средствам измерения с учетом объема измерительной ячейки и достигнутой чувствительности к измеряемому параметру. С использованием микрокалориметра ДМК-1 был исследован большой объем веществ и образцов ТСМ.

Таким образом, специалисты ИТТФ внесли существенный вклад в решение проблемы термометрирования разрушенного блока ЧАЭС.

\section{2. ПРОГНОЗИРОВАНИЕ ТЕПЛОВОГО СОСТОЯНИЯ «ОБЪЕКТА УКРЫТИЕ»}

В 1988-89 годах руководство ЧАЭС волновал вопрос теплового состояния активной массы разрушенного блока ЧАЭС. Главным из них был вопрос выделения теплоты остатками активной массы и в этой связи прогноз температуры разрушенного реактора. При ликвидации аварии в 1986 году в разрушенную часть блока вертолетами сверху были набросаны десятки тонн различных веществ для снижения радиоактивных выбросов и замедления реакции топлива, что также влияло на температуру остатков топлива. Было построено укрытие блока (рис. 8, $a$ ) и рассматривался также вопрос об усилении изоляции разрушенной части реакторного блока ЧАЭС от окружающей среды. В частности, рассматривались варианты заливки бетоном пространства под перевернутой крышкой реактора. Бетон хорошо бы изолировал разрушенную часть реакторного блока, но существенно препятствовал бы охлаждению остатков активной массы. Поэтому рассматривался также вариант засыпки этого пространства керамзитом и обрезками стальных труб, что сохраняло бы возможность охлаждения активной массы.

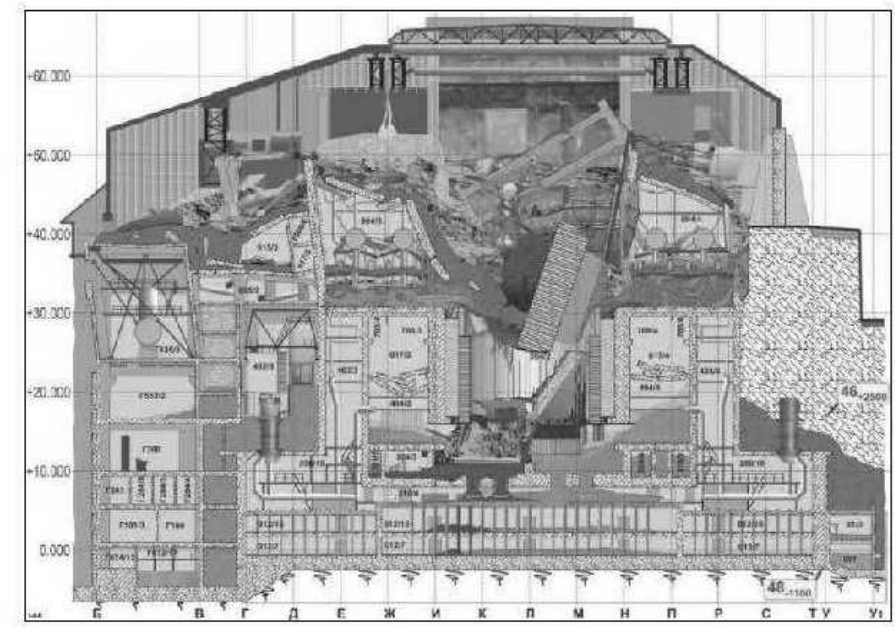

a)

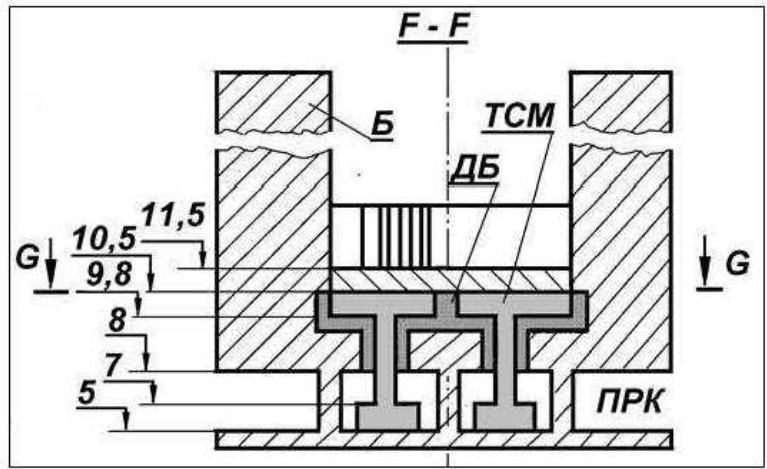

б)

Рис. 8. Рисунок разрушенного 4-го энергоблока ЧАЭС (а) и схема модели с топливосодержацими массами в подреакторном пространстве (б).

В этой связи руководство ЧАЭС обратилось к ученым ряда научных центров страны, в частности к ИТТФ, с просьбой рассчитать и спрогнозировать тепловой режим разрушенного реактора в существующем состоянии и для различных вариантов засыпки пространства под сдвинутой крышкой реактора. ИТТФ принял активное участие в этой работе, выполнил ее, и два представителя института П.Г.Круковский и Г.В.Коваленко весной 1989 г. выезжали в г. Чернобыль для сдачи работы и обсуждения ее результатов на специальном совещании. На совещании присутствовали представители других научных центров страны, в частности, Института тепломассообмена, г. Минск, Московского авиационного института, которым также была поручена эта работа. Представители институтов сравнивали свои результаты, проходило их обсуждение. 
Для образовавшейся композиции при измеренном и предполагаемых тепловыделениях решалось уравнение теплопроводности при известных начальных и граничных условиях. Как и предполагалось, наибольшая температура наблюдалась на оси юго-восточного клапана. При суммарном тепловыделении 22,3 кВт и свободном доступе воздуха в подреакторное пространство максимум температуры составил бы не более $220{ }^{\circ} \mathrm{C}$, при полной теплоизоляции боковой п оверхности трубы клапана $-315^{\circ} \mathrm{C}$.

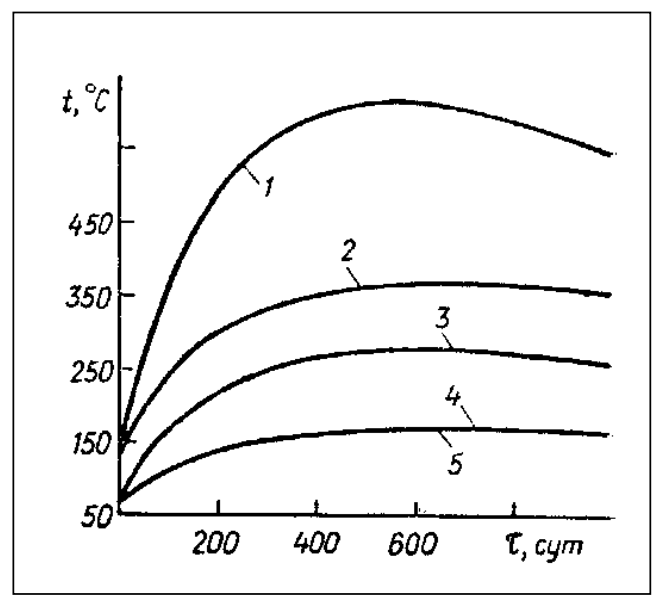

Рис. 9. Изменения во времени максимальной температуры тепловыделяющих масс;

1, 3 - после засыпки керамзитом;

2, 4 - бетоном; 5 - обрезками труб;

(1, 2 - труба клапана теплоизолирована). 3, 4,5 - свободный доступ воздуха в ПРК.

Расчет температур (рис. 9) композиций производился для сравнения трех вариантов укрепления шахты реактора. Первый вариант - заливка шахты бетоном; второй - засыпка шахты керамзитом; третий - засыпка свободного пространства шахты обрезками труб диаметром 0,1 м. Наихудшим вариантом оказался случай засыпки шахты мало теплопроводным керамзитом. Через 600 суток при сохранении конвекции воздуха в ПРК температура достигнет $280{ }^{\circ} \mathrm{C}$, а при полной теплоизоляции трубы клапана - $400{ }^{\circ} \mathrm{C}$, что недопустимо c точки зрения прочности бетона. Варианты - заливка шахты бетоном и засыпка шахты обрезками труб показали похожие результаты. Максимумы температур достигались по истечении 700 суток и составляли соответственно $160{ }^{\circ} \mathrm{C}$ и $356{ }^{\circ} \mathrm{C}$ в зависимости от сохранения или отсутствия конвекции в ПРК.

Общим, совпадающим у всех исполнителей этой работы, был вывод о том, что возможна ситуация, когда остатки активной массы в реакторе не достигнут опасного разогрева, а рассмотренные варианты засыпки пространства под нарушенной крышкой реактора будут в той или иной мере влиять на уровень и темп охлаждения реактора.

Таким образом, специалисты ИТТФ в области моделирования процессов теплообмена внесли еще один вклад в решение проблем разрушенного блока ЧАЭС.

\section{3.АНАЛИЗ И ПРОГНОЗИРОВАНИЕ ТЕРМОГАЗОДИНАМИЧЕСКИХ ПРОЦЕССОВ В НОВОМ БЕЗОПАСНОМ КОНФАЙНМЕНТЕ И «ОБЬЕКТЕ УКРЫТИЕ» ЧАЭС}

После этого в ИТТФ в отделе моделирования процессов тепломассообмена (руководитель П.Г.Круковский) продолжались и продолжаются работы по решению и других проблем разрушенного блока и строящегося так называемого Нового Безопасного Конфайнмента (НБК), который является защитным сооружением, включающим в себя комплекс технологического оборудования для извлечения из разрушенного четвёртого энергоблока Чернобыльской АЭС материалов, содержащих ядерное топливо и обращения с радиоактивными отходами, а также другие системы, предназначенные для осуществления деятельности по преобразованию этого энергоблока в экологически безопасную систему и обеспечение безопасности персонала, населения и окружающей среды.

НБК представляет собой комплекс из трех инженерно-технических решений: стальных конструкций в виде Арки, накрывающих Объект «Укрытие» (ОУ), технологического здания, расположенного в западной части Арки, где будет установлено большинство систем жизнеобеспечения и контроля, и вспомогательного здания, в котором будут находиться другие системы. 
Для обеспечения защиты окружающей среды и гарантирования долговременного сопротивления коррозии, структурная часть Арки (рис. 10, позиция 1) внутри и снаружи будет обшита двумя металлическими оболочками, - внешней 2 и внутренней 3.
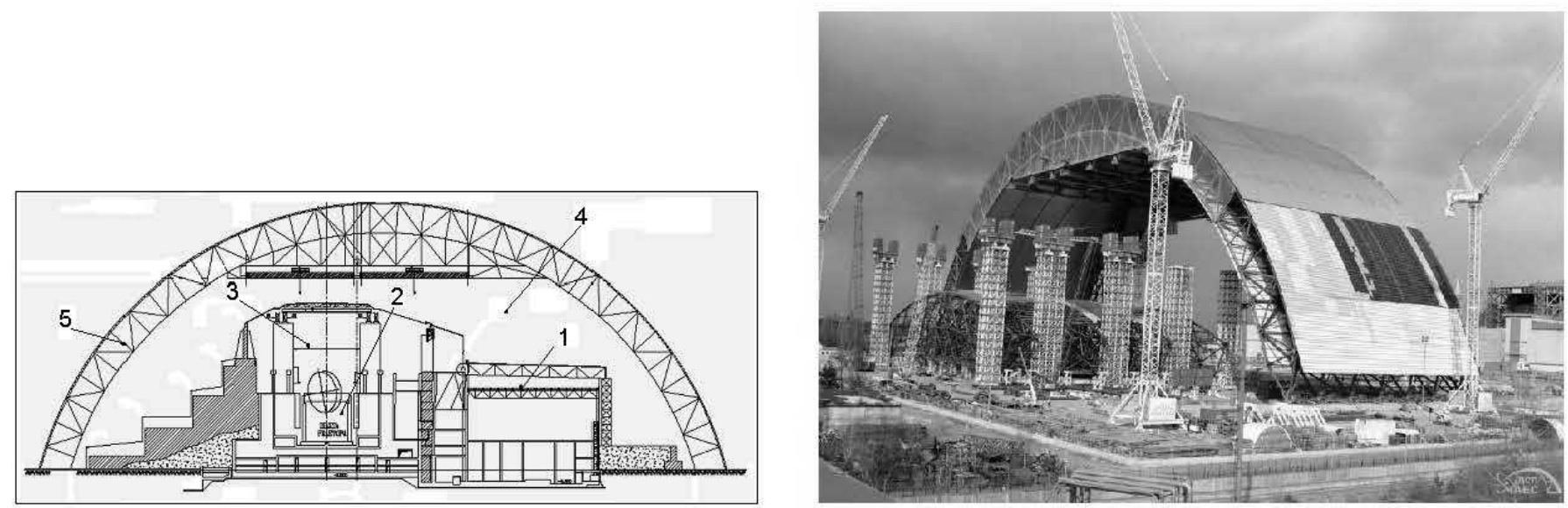

\section{Рис. 10. Схема Обьекта «Укрытие» и Нового Безопасного Конфайнмента в поперечном сечении (а) и фото частично собранного НБК (октябрь 2014 2.)}

(б: 1 -машзал, 2 - разрушенный реактор, 3 -Объект «Укрытие», 4-основной объем НБК, 5 - стальные конструкции и кольцевое пространство Арки НБК.

В кольцевом пространстве и основном объеме предусматриваются системы вентиляции, которые должны обеспечить требуемый режим влажности (с целью снижения до минимума коррозии металлических конструкций кольцевого пространства) и предотвратить попадание аэрозольных выбросов в окружающую среду, которые могут внезапно возникнуть в основном объеме Арки при демонтаже конструкций ОУ.

Новый Безопасный Конфайнмент спроектирован и строится консорциумом VINCI Construction Grands Projets / Bouygues Travaux Publics NOVARKA (HOBAPKA) и будет закончен в 2017 году. Он должен предотвратить утечки радиоактивных материалов из разрушенного реактора №4 в окружающую среду при его разборке. Общие геометрические размеры Арки НБК составляют: высота около 109 м, длина около 164 м, ширина около 260 м. Общий вес Арки составляет около 33 тыс. тонн.

Ниже будут описаны модели и результаты анализа и прогнозирования термогазодинамических процессов в НБК и ОУ, которые непосредственно влияют на безопасность, работоспособность и ресурс самого НБК.

Одной из таких задач была задача пожарной безопасности НБК. Интересные и важные из них были выполнены в 2005 и 2010 г. и были связаны с оценкой огнестойкости (время до начала обрушения из-за перегрева) несущих конструкций арочного свода Нового Безопасного Конфайнмента (НБК) при выгорании горючей части покрытия крыши машзала 4-го блока ЧАЭС (рис. 11). Информация о назначении и конструкции НБК приводится в следующем разделе.

Сотрудники отдела выступали как в качестве исполнителей этой работы, так и в качестве экспертов при совместной работе с французской фирмой «Эффектис».

Следующей задачей была задача анализа работоспособности и устойчивости при авариях одной из важных инженерных систем НБК - системы вентиляции (рис. 11), которая прежде всего должна обеспечить требуемый режим относительной влажности (не более 40 \%) и уровень превышения давления воздуха (50..75 Па) в кольцевом пространстве Арки НБК, а также вентиляцию и поддержание слабого вакуума ( $\approx-5$ Па) в основном обьеме Арки НБК при различных метеорологических условиях. Необходимость поддержания низкого уровня относительной 
влажности в кольцевом пространстве Арки НБК продиктована требованием снижения до минимума коррозии металлических конструкций, расположенных в кольцевом пространстве, для обеспечения 100-летнего ресурса Арки НБК. Для проверки проекта и анализа работы системы вентиляции НБК в различных метерологических условиях и в условиях отказов консорциум НОВАРКА в 2010 г. обьявил тендер на выполнение таких работ с помощью моделирования. ИТТФ выйграл этот тендер и отдел моделирования процессов тепломассообмена в течение 2,5 лет выполнял эту работу. Работа выполнялась с помощью созданной сложной трехмерной модели, описывающей теплогазодинамические и влажностные процессы в НБК и ОУ с учетом всех систем вентиляции и осушения воздуха.

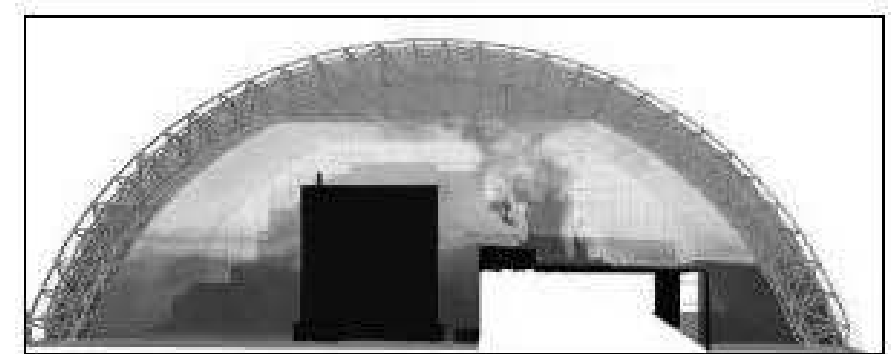

\section{Рис. 11. Поле температур в объёме НБК при пожаре на крыше машзала.}

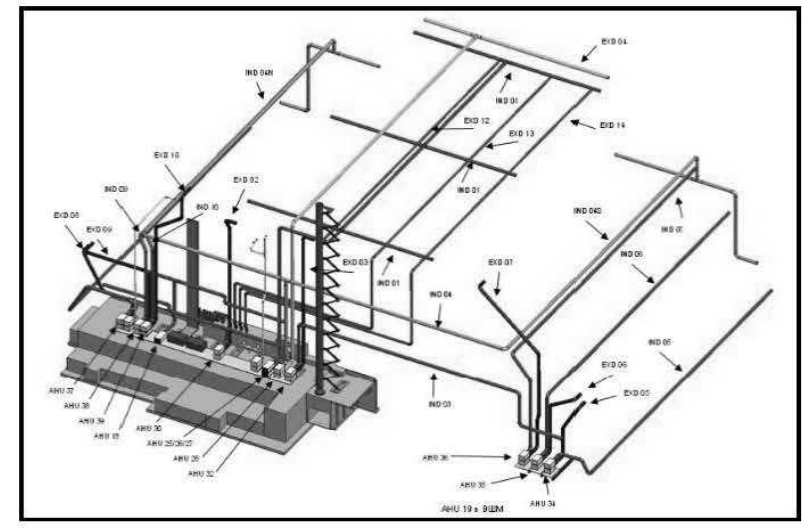

Рис. 12. Схема системы вентиляции НБК.

Система вентиляции состоит из двух подсистем - подситемы вентиляции и осущения кольцевого пространства для обеспечения указанного выше уровня относительной влажности воздуха и подсистемы вентиляции основного обьема НБК для обеспечения поступления свежего воздуха в места работы персонала НБК и отвода воздуха из мест с наибольшим количеством радиоактивных аэрозолей, прежде всего пространства над ОУ (рис. 12).

Ниже приводится краткое описание выбранной модели и основные результаты ее применения для детального анализа работоспособности системы вениляции НБК. Модель учитывала основные температурные и газодинамические процессы, происходящих в НБК и ОУ.

Для этого была создана 3D CFD-модель, включающая в себя как части модели Арки НБК, так и всех объектов под Аркой, включая Объект «Укрытие», грунты и фундаменты (рис. 13).
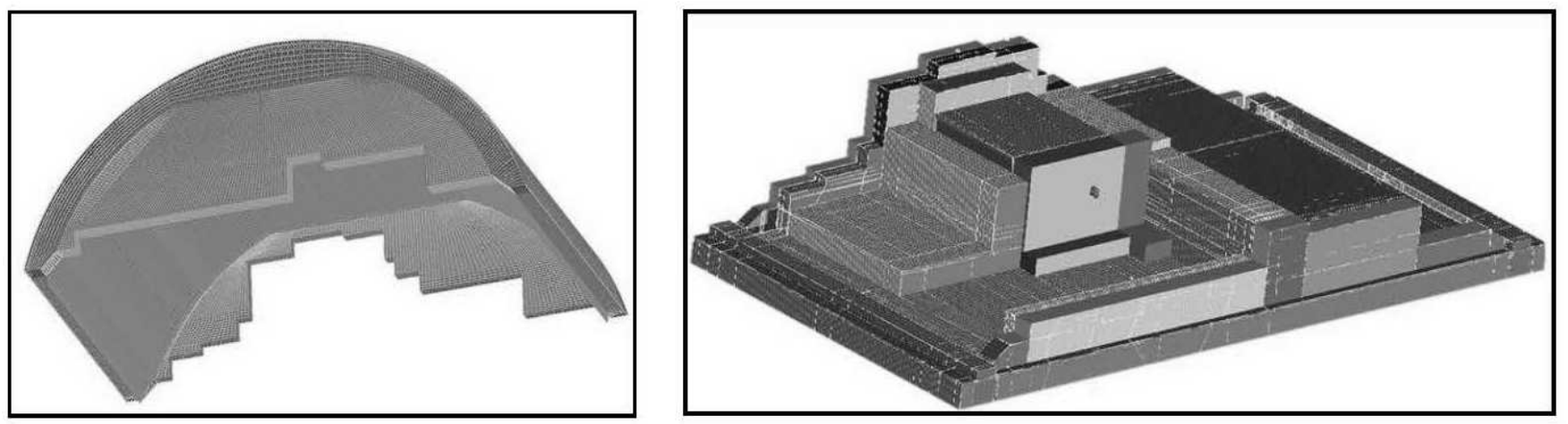

Рис. 13. Части геометрических и сеточных моделей Арки НБК (а) и всех о бъектов под Аркой, включая Объект «Укрытие», грунты и фундаменты (б). 
Граничные условия на внешней оболочке Арки НБК задавались в виде условий радиационноконвективного теплообмена и условий массообмена слабофильтрующегося воздуха и влажности между поверхностями оболочки и внешней средой при задании давлений на этих оболочек, соответствующих направлению и силе ветра, обтекающего НБК. Между всеми твердыми поверхностями НБК, ОУ, поверхностью земли и воздухом, обтекающим эти поверхности, задавались условия сопряженного теплообмена. Воздухо- и влагообмен между основным объемом и окружающей средой осуществлялся посредством системы вентиляции и протечек воздуха и влаги из окружающей среды через щели между вертикальными стенами Арки НБК и строительными конструкциями ОУ. Величина этих протечек также зависит от направления и силы ветра, обтекающего НБК. Влияние земли и фундаментов учитывалось посредством включения в основную модель области решения и дополнительной сетки, охватывающей грунт и фундаменты под Аркой НБК на глубину 15 м.

Разработанная и кратко описанная выше модель термогазодинамических и влажностных процессов в воздушных обьемах Арки НБК, всех строительных конструкциях ОУ и фундаментах и грунтах под ними была использована для детального анализа распределения температуры и влажности в кольцевом и основном объемах НБК и ОУ при различных климатических условиях в стационарных и нестационарных режимах, а также прогнозировании тепловлажностного состояния ОУ и НБК при отказах различных частей вентиляционного оборудования. На рис. 14 приведен пример такого распределения температуры и влажности в кольцевом и основном объемах НБК и ОУ при стационарном режиме в летнее время при температуре окружающего воздуха $30{ }^{\circ} \mathrm{C}$, относительной влажности 100 \% и отсутствии ветра.

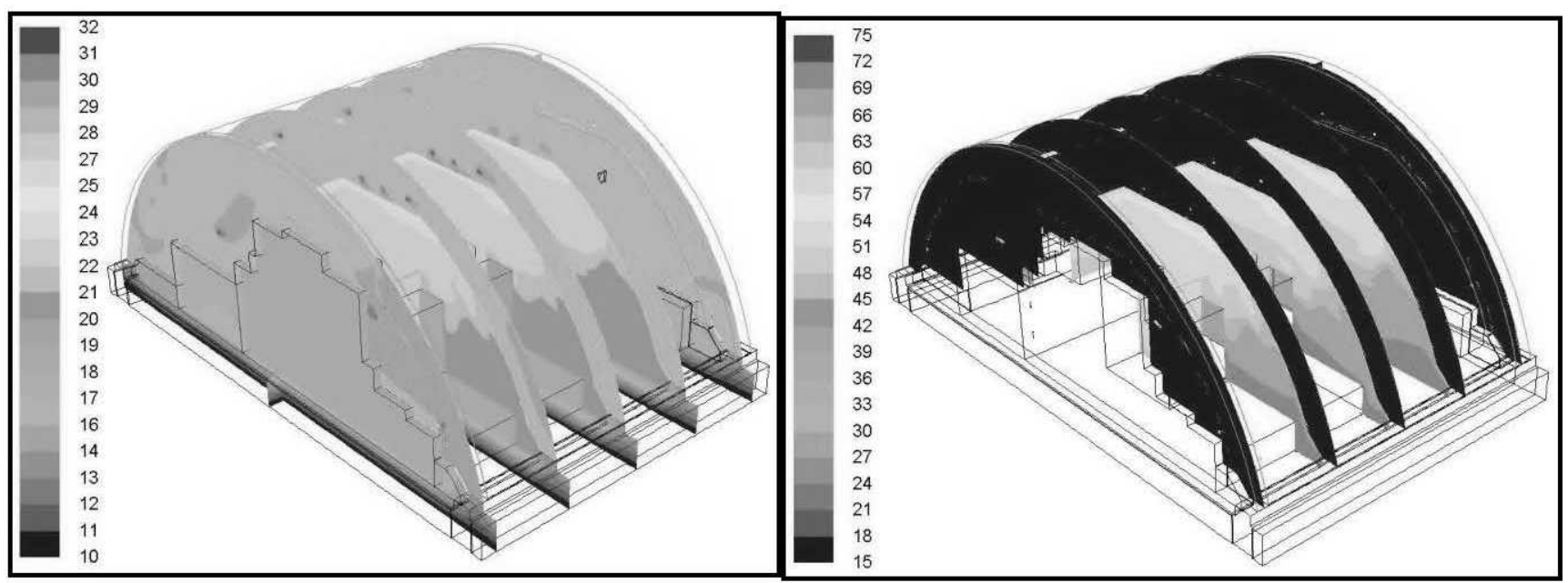

Рис. 14. Распределения температур (а) и влажности (б) в кольцевом и основном объемах ОУ и НБК.

Проведенные исследования показали, что система вентиляции в целом работоспособна в диапазоне заданных климатических условий с изменением температуры окружающего воздуха от -22 до $+30{ }^{\circ} \mathrm{C}$, относительной влажности от 50 до $100 \%$ и силе ветра от 0 до 25 м/с.

Таким образом, специалисты ИТТФ в области моделирования процессов теплообмена внесли очередной вклад в решение проблем разрушенного блока ЧАЭС, а именно в проектирование Нового Безопасного Конфайнмента, который должен будет обеспечить (в течение 100 лет) демонтаж Объекта Укрытие и полную разборку разрушенного блока с конечной целью превращения этой зоны в безопасную экологически чистую зону. 


\section{Заключение}

Изложенные выше работы, выполненные сотрудниками ИТТФ в различные годы на протяжении 30 лет, не закончены и продолжаются, так же, как и сотрудничество с Чернобыльской АЭС и работниками консорциума НОВАРКА. Консорциум предполагает закончить строительство уникального, не имеющего аналогов в мире сооружения НБК над разрушенным блоком, к концу 2017 г. Такое сотрудничество сопровождается возможностью посещения ЧАЭС, ОУ и НБК для встреч, совещаний и семинаров, на которых представляются и обсуждаются полученные в ИТТФ результаты. Так в 2012 г. делегация ИТТФ в составе директора А.А.Долинского (на фото (а) в центре), П.Г.Круковского (справа) и М.А.Метель (слева) посетили площадку возле ОУ и НБК (начало строительства), а также в г. Чернобыль выступили перед сотрудниками ЧАЭС с докладами о результатах моделирования ОУ и НБК.

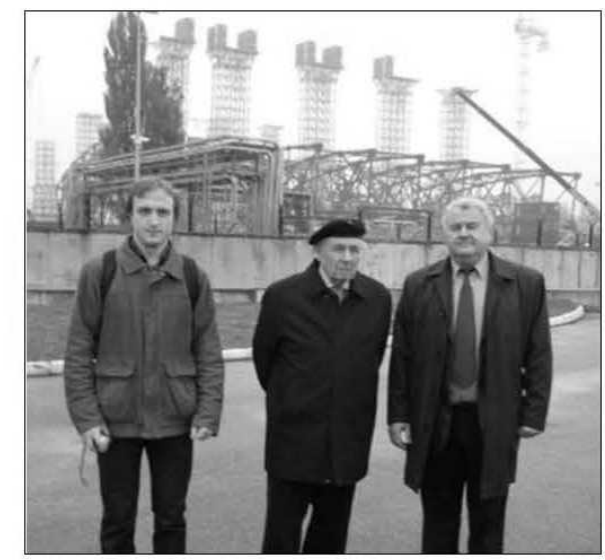

a)

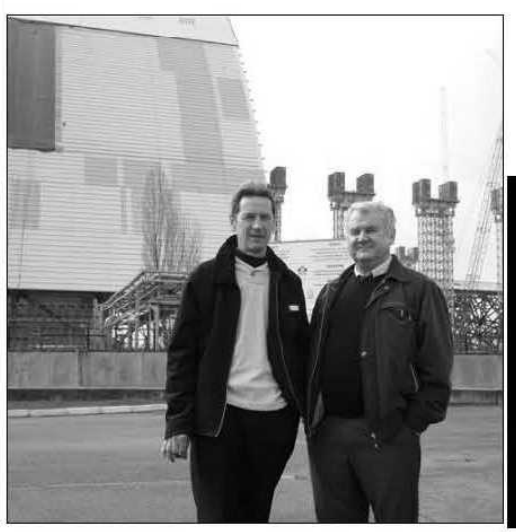

б)

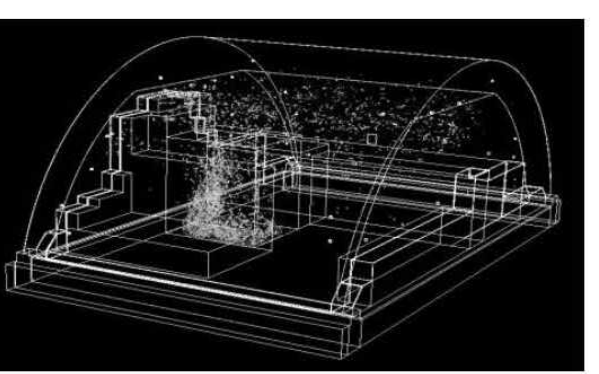

в)

В 2014 г. П.Г.Круковский (на фото (б) справа) совместно с сотрудником Института проблем безопасности АЭС НАНУ Красновым В.А. (слева) посетили НБК (середина строительства), а также представили и обсудили результаты моделирования ОУ и НБК группе управления проектом НБК. В настоящее время работа продолжается в направлении совершенствования моделей анализа и прогнозирования термогазодинамического состояний ОУ и НБК и на их основе радиоактивного загрязнения объёма НБК аэрозолями (рис. в) для прогнозирования влияния на персонал и окружающую среду. Такие модели планируется ввести в систему мониторинга термогазодинамического и радиационного состояний ОУ и НБК, что позволит продолжить сотрудничество с ЧАЭС еще на долгие годы. 


\section{WORKS OF THE INSTITUTE OF ENGINEERING THERMOPHYSICS ON THE SOLUTION TO THE PROBLEMS OF THE DESTROYED REACTOR AND NEW CONFINEMENT \\ (to the 30th anniversary of the Chernobyl accident)}

\section{T.G. Grishchenko, P.G. Krukovskyi, G.V. Kovalenko, LV. Dekusha, L.I. Vorobiev, M.A. Metel, A.S. Polubinsky}

Institute of Engineering Thermophysics of the National Academy of Sciences of Ukraine, vul. Zhelyabova, 2a, Kyiv, 03680, Ukraine

Key words: Chernobyl nuclear power plant accident, temperature transducers and measuring, computer simulation, Safe Confinement.

An activities review of employees of IETP of NAS of Ukraine on the mitigation of the implications of the accident at Unit 4 of the Chernobyl nuclear power plant, April 26, 1986 is shown. To identify and study nuclear fuel and fuel-containing material accumulation places heat flow and temperature transducers have been developed and manufactured. The work on the forecasting of probable warming up of the destroyed reactor due to being filled with various materials (concrete, expanded clay and scraps of steel pipes) was performed. Computer models were developed and the results of the analysis and forecasting of heat and gas dynamic processes are presented for the New Safe Confinement and "Object Shelter" of the Chernobyl nuclear power plant in order to verify the fitting to defined criteria of engineering systems performance.

Получено 15.03.2016

Received 15.03.2016 